\title{
Angka kejadian afasia pada stroke di Instalasi Rehabilitasi Medik RSUP Prof. Dr. R. D. Kandou Manado tahun 2015
}

\author{
${ }^{1}$ Andrew M. Purnomo \\ ${ }^{2}$ Lidwina S. Sengkey \\ ${ }^{2}$ Christina A. Damopolii \\ ${ }^{1}$ Kandidat Skripsi Fakultas Kedokteran Universitas Sam Ratulangi Manado \\ ${ }^{2}$ Bagian Ilmu Kedokteran Fisik dan Rehabilitasi Fakultas Kedokteran \\ Universitas Sam Ratulangi Manado \\ Email: andrewmkrs@gmail.com
}

\begin{abstract}
Aphasia is a general term used to define a set of language disorder that occurs after brain damage commonly in the left hemisphere. The most underlying etiology of aphasia is cerebrovascular disease, stroke. Aphasia is present in $21-38 \%$ of patients with acute stroke and its impact is associated with short-term and long-term morbidity, high mortality rates, and limitations of the patients socialization. So as to raise awareness of disability caused by stroke, especially aphasia, it is necessary to know the incidence of aphasia in stroke patients in the Medical Rehabilitation Installation of Prof. Dr. R. D. Kandou Manado Hospital in 2015. This was retrospective descriptive study with a cross sectional design using data from medical records. Of the 455 stroke patients, $60(13,2 \%)$ were aphasic. The youngest age of aphasic patients was 30 years old and the oldest one was 85 years old. The incidence of aphasia was more common in the age above 60 years (40\%), non hemorrhagic stroke $(60 \%)$, and in patients with right hemiparesis $(78,3 \%)$. However, there were $6(10 \%)$ aphasic patients with left hemiparesis. Conclusion: In the Medical Rehabilitation Installation of Prof. Dr. R. D. Kandou Manado Hospital in 2015, the incidence of aphasia was $13.2 \%$. There was an increasing incidence of aphasia in each decade over the age of 30 years. No significant differences between the genders and types of stroke. Aphasia was also f ound in patients with left hemiparesis which signified the involvement of the right hemisphere.
\end{abstract}

Keywords:aphasia, stroke, medical rehabilitation

\begin{abstract}
Abstrak: Afasia adalah istilah umum yang digunakan untuk mendefinisikan sekumpulan gangguan berbahasa yang terjadi setelah adanya kerusakan otak, yang sering mengenai hemisfer sebelah kiri. Etiologi yang paling banyak mendasari afasia ialah penyakit serebrovaskular, yaitu stroke. Afasia terdapat pada 21-38\% pasien stroke akut dan dampaknya dikaitkan dengan morbiditas jangka pendek dan jangka panjang, tingginya angka mortalitas, dan keterbatasan pasien dalam sosialisasi. Penelitian ini bertujuan untuk mengetahui angka kejadian afasia pada stroke di Instalasi Rehabilitasi Medik RSUP Prof. Dr. R. D Kandou Manado tahun 2015. Jenis penelitian ialah deskriptif retrospektif dengan desain potong lintang menggunakan data dari rekam medik. Hasil penelitian memperlihatkan dari 455 pasien stroke, $60(13,2 \%)$ diantaranya mengalami afasia. Usia paling muda pasien dengan afasia ialah 30 tahun dan usia paling tua ialah 85 tahun. Angka kejadian afasia lebih banyak terjadi pada usia di atas 60 tahun $(40 \%)$, stroke non hemoragik $(60 \%)$, dan pasien dengan hemiparesis dekstra (78,3\%). Terdapat $6(10 \%)$ pasien afasia dengan hemiparesis sinistra. Simpulan:Angka kejadian afasia pada tahun 2015 ialah 13,2\%. Adanya peningkatan angka kejadian afasia pada tiap dekade usia di atas 30 tahun. Tidak ada perbedaan bermakna antara jenis kelamin dan jenis stroke. Pasien dengan hemiparesis sinistra juga mengalami afasia yang menandakan keterlibatan hemisfer dekstra.
\end{abstract}

Kata kunci: afasia, stroke, rehabilitasi medik 
Afasia adalah suatu istilah umum yang digunakan untuk mendefinisikan sekumpulan gangguan berbahasa yang terjadi setelah adanya kerusakan otak, yang sering mengenai hemisfer kiri. Afasia dapat mempengaruhi aspek ekspresif maupun reseptif dalam komunikasi termasuk berbicara, pemahaman, menulis, membaca dan gerak/isyarat, sehingga afasia merupakan salah satu defisit kognitif yang paling membatasi pasien karena menyebabkan cacat fungsional dan tekanan psikologis yang parah. ${ }^{1,2}$

Afasia terjadi akibat lesi yang secara akut dapat disebabkan oleh stroke atau cedera kepala, dan dapat juga terjadi perlahan akibat adanya tumor otak. Etiologi yang paling banyak mendasari afasia adalah penyakit serebrovaskular, yaitu stroke. ${ }^{3}$ Stroke adalah gejala klinis akibat adanya ganggguan fungsi serebral yang bersifat fokal maupun global yang berkembang secara cepat, berlangsung lebih dari 24 jam atau menyebabkan kematian, dimana bukan disebabkan hal lain selain daripada kelainan vaskular. Stroke secara klasik ditandai dengan defisit neurologis akibat kerusakan fokal yang disebabkan oleh gangguan vaskular yang sewaktu-waktu dapat timbul. ${ }^{4,5}$

Stroke merupakan penyakit yang secara umum menyebabkan disabilitas fisik, termasuk didalamnya ialah gangguan komunikasi atau berbahasa. Afasia terdapat pada $21-38 \%$ pasien stroke akut dan dampaknya dikaitkan dengan morbiditas jangka pendek dan jangka panjang, tingginya angka mortalitas, dan keterbatasan pasien dalam bersosialisasi. ${ }^{2,6,7} \mathrm{Di}$ tempat rehabilitasi pasien akut, pasien stroke dengan afasia memiliki jangka waktu pemulihan yang lebih lama dan menunjukkan perbaikan fungsional yang lebih buruk dibandingkan pasien stroke tanpa afasia. ${ }^{1}$

Dari data Riset Kesehatan Dasar 2013, stroke telah menjadi penyebab kematian utama hampir di semua rumah sakit di Indonesia (14,5\%). Sulawesi Utara merupakan daerah dengan prevalensi kasus stroke tertinggi, yaitu $10,18 \% .^{8}$
Dalam data statistik pasien tahun 2012, dari 10 penyakit terbanyak di Instalasi Rehabilitasi Medik RSUP Prof. Dr. R. D Kandou Manado, stroke menempati posisi kedua dengan persentase 24\%. Demikian halnya dengan tahun 2013 dimana stroke tetap menempati posisi kedua dengan persentase $26,6 \%$. Sedangkan pada tahun 2014 , terdapat sedikit penurunan persentase penyakit stroke menjadi $26 \%$.

Sepertiga dari pasien stroke baru mengalami afasia. Kemajuan rehabilitasi penderita afasia masih jauh tertinggal abila dibandingkan dengan strategi penanganan stroke akut maupun terapi defisit motorik lainnya yang disebabkan oleh stroke. ${ }^{6}$ Untuk meningkatkan kesadaran akan disabilitas yang disebabkan stroke terutama afasia, dikaitkan dengan morbiditas, tingginya angka mortalitas dan keterbatasan pasien dalam bersosialisasi, maka penulis merasakan perlunya untuk mengetahui angka kejadian afasia pada stroke di Instalasi Rehabilitasi Medik RSUP Prof. Dr. R. D Kandou Manado tahun 2015. Diharapkan penelitian ini dapat memberikan data yang akurat mengenai jumlah pasien dengan afasia.

\section{METODE PENELITIAN}

Jenis penelitian ini ialah deskriptif retrospektif dengan menggunakan data dari rekam medik dan dilakukan melalui desain potong lintang. Penelitian dilakukan di Instalasi Rehabilitasi Medik RSUP Prof. Dr. R. D Kandou Manado dalam kurun waktu tiga bulan selama bulan AgustusOktober 2016. Pasien yang diambil menjadi sampel ialah yang memenuhi kriteria inklusi: pasien yang didiagnosis menderita stroke dengan afasia, baik stroke hemoragik maupun stroke non hemoragik dan merupakan pasien yang datang berobat di Instalasi Rehabilitasi Medik RSUP Prof. Dr. R. D Kandou Manado pada periode Januari-Desember 2015. Pasien yang masuk kriteria eksklusi alah pasien dengan rekam medik yang tidak lengkap. Variabel penelitian ini adalah usia, jenis kelamin, stroke hemoragik, stroke non hemoragik, dan hemiparesis. Setelah data sekunder dari 
rekam medik telah dikumpulkan, dilakukan pengolahan data dengan menggunakan analisis univariat SPSS 23 dan hasil penelitian disajikan dalam bentuk tabel dan diagram.

\section{HASIL PENELITIAN}

Dari penelitian yang telah dilakukan di Instalasi Rehabilitasi Medik RSUP Prof. Dr. R. D Kandou Manado sejak bulan Agustus 2016 hingga Oktober 2016, didapatkan 455 pasien stroke yang memenuhi kriteria inklusi dan 12 pasien stroke yang tidak memiliki data rekam medik yang lengkap sehingga dieksklusi.

Dari 455 pasien stroke pada tahun 2015, $60(13,2 \%)$ diantaranya mengalami afasia, dan $395(86,8 \%)$ pasien lain mengalami stroke tanpa afasia. Usia paling muda pasien dengan afasia adalah 30 tahun dan usia paling tua adalah 85 tahun. Dari 3 pasien stroke dengan usia di bawah 30 tahun, tidak ada yang mengalami afasia. Pada rentang usia 30-39 tahun didapatkan 5 pasien afasia dari 29 pasien stroke, selanjutnya pada rentang usia 40-49 tahun didapatkan 15 pasien afasia dari 70 pasien stroke, pada rentang usia 50-59 terdapat 16 pasien afasia dari 141 pasien stroke dan pada usia diatas 60 terdapat 24 pasien afasia dari 212 pasien stroke (Tabel 1)

Tabel 1. Angka kejadian afasia pada stroke berdasarkan usia di Instalasi Rehabilitasi Medik RSUP Prof. Dr. R. D Kandou Manado tahun 2015

\begin{tabular}{ccccc}
\hline Usia & Stroke & $\boldsymbol{\%}$ & Afasia & \% \\
\hline$<30$ & 3 & 0,7 & 0 & 0 \\
$30-39$ & 29 & 6,4 & 5 & 8,3 \\
$40-49$ & 70 & 15,4 & 15 & 25 \\
$50-59$ & 141 & 31 & 16 & 26,7 \\
$\geq 60$ & 212 & 46,6 & 24 & 40 \\
Total & 455 & 100 & 60 & 100 \\
\hline
\end{tabular}

Dari 455 pasien stroke, didapatkan 268 $(58,9 \%)$ pasien laki-laki dan $187(41,1 \%)$ pasien perempuan dan dari 60 pasien afasia, terdapat $35(58,3 \%)$ pasien laki-laki dan $25(41,7 \%)$ pasien perempuan Pada 268 pasien stroke laki-laki, terdapat 35
(13\%) pasien dengan afasia dan dari 187 pasien stroke perempuan terdapat 25 (13\%) pasien dengan afasia (Tabel 2).

Tabel 2. Angka kejadian afasia pada stroke berdasarkan jenis kelamin di Instalasi Rehabilitasi Medik RSUP Prof. Dr. R. D Kandou Manado tahun 2015

\begin{tabular}{lcccc}
\hline $\begin{array}{l}\text { Jenis } \\
\text { kelamin }\end{array}$ & Stroke & $\%$ & Afasia & $\%$ \\
\hline Laki-Laki & 268 & 58,9 & 35 & 58,3 \\
Perempuan & 187 & 41,1 & 25 & 41,7 \\
$\quad$ Total & 455 & 100 & 60 & 100 \\
\hline
\end{tabular}

Berdasarkan tipe stroke, dari 455 pasien, terdapat $152(33,4 \%)$ pasien stroke hemoragik dan $303(66,6 \%)$ pasien stroke non hemoragik. Pada 60 pasien afasia, 24 $(40 \%)$ diantaranya dengan stroke hemoragik dan $36(60 \%)$ pasien dengan stroke non hemoragik (Tabel 3).

Tabel 3. Angka kejadian afasia pada stroke hemoragik dan non hemoragik di Instalasi Rehabilitasi Medik RSUP Prof. Dr. R. D Kandou Manado tahun 2015

\begin{tabular}{ccccc}
\hline Tipe Stroke & N & $\%$ & Afasia & $\%$ \\
\hline Hemoragik & 152 & 33,4 & 24 & 40 \\
Non-Hemoragik & 303 & 66,6 & 36 & 60 \\
Total & 455 & 100 & 60 & 100 \\
\hline
\end{tabular}

Dari 60 pasien afasia, $47(78,3 \%)$ pasien mengalami hemiparesis dekstra, 6 $(10 \%)$ hemiparesis sinistra, $5 \quad(8 \%)$ hemiparesis dupleks dan $2(3,3 \%)$ pasien tanpa kelemahan.

Tabel 4. Angka kejadian afasia pada stroke berdasarkan sisi tubuh yang terkena di Instalasi Rehabilitasi Medik RSUP Prof. Dr. R. D Kandou Manado tahun 2015

\begin{tabular}{ccccc}
\hline Hemiparesis & N & \% & Afasia & \% \\
\hline Dekstra & 207 & 45,5 & 47 & 78,3 \\
Sinistra & 195 & 42,9 & 6 & 10 \\
Dupleks & 17 & 3,7 & 5 & 8 \\
Tanpa kelemahan & 36 & 7,9 & 2 & 3,3 \\
Total & 455 & 100 & 60 & 100 \\
\hline
\end{tabular}




\section{BAHASAN}

Dari hasil penelitian mengenai angka kejadian afasia pada stroke di Instalasi Rehabilitasi Medik RSUP Prof. Dr. R. D Kandou Manado tahun 2015 yang telah dilakukan sejak bulan Agustus 2016 hingga Oktober 2016, didapatkan 455 pasien stroke dan $60 \quad(13,2 \%)$ diantaranya mengalami afasia. Angka ini lebih rendah daripada penelitian-penelitian lain yang menyatakan insidens afasia sebesar 35$39,9 \%$ pada pasien stroke. ${ }^{10-12}$

Dari 60 pasien afasia, jenis afasia yang paling banyak tecatat ialah afasia Broca sebanyak 25 pasien. Juga tercatat 10 pasien afasia Global, 4 pasien afasia Wernicke, dan 2 pasien afasia transkortikal. Terdapat 19 rekam medik yang tidak mencatat jenis afasia pasien.

Berdasarkan usia, angka kejadian afasia terus meningkat setiap dekade setelah usia 30 tahun. Didapatkan 3 pasien stroke dibawah 30 tahun, namun tidak ada yang mengalami afasia. Pada rentang usia 30-39 tahun didapatkan $5(8,3 \%)$ pasien afasia, selanjutnya pada rentang usia 40-49 tahun didapatkan 15 (25\%) pasien afasia dan pada rentang usia 50-59 terdapat 16 $(26,7 \%)$ pasien afasia. Jumlah ini terus meningkat pada usia diatas 60, dimana terdapat $24(40 \%)$ pasien afasia. Seiring meningkatnya usia, resiko stroke semakin meningkat dan sebagian besar memiliki penyakit lain yang mendasari. ${ }^{5}$ Denikian juga dengan angka kejadian afasia yang banyak didapatkan pada pasien geriatri. ${ }^{13}$ Hal ini sesuai dengan yang dilaporkan dari penelitian-penelitian sebelumnya yang menyebutkan bahwa insidens afasia pada usia lanjut semakin tinggi. ${ }^{10,14}$

Dari 268 pasien stroke dengan jenis kelamin laki-laki, 35 (13\%) diantaranya mengalami afasia. Dari 187 pasien stroke dengan jenis kelamin perempuan didapatkan $25(13,4 \%)$ pasien afasia. Hal ini sebanding dengan penelitian oleh De Renzi et al. $^{14}$ pada 200 pasien afasia yang menyatakan tidak ada perbedaan kejadian afasia pada pasien laki-laki dan perempuan. Hasil penelitian ini berbeda dengan penelitian Hier et al. ${ }^{15}$ pada Stroke Data
Bank yang menyatakan bahwa kejadian afasia pada perempuan lebih tinggi, dimana $19,4 \%$ laki-laki dan $22,5 \%$ perempuan pasien stroke mengalami afasia.

Berdasarkan tipe stroke, dari 60 pasien afasia, 24 (40\%) pasien mengalami stroke hemoragik dan $36(60 \%)$ mengalami stroke non hemoragik. Banyaknya kasus stroke non hemoragik dibandingkan stroke hemoragik dapat dikaitkan dengan patologi vaskular intrakranial yang mendasari, seperti aterosklerosis, atau patologi dengan sumber yang lebih jauh seperti emboli dari penyakit arteri ekstrakranial atau jantung, ataupun berkurangnya perfusi serebral karena kegagalan sirkulasi. Penyakit pembuluh darah besar meliputi patologi yang melibatkan pembuluh darah karotis ekstrakranial dan arteri intrakranial, termasuk cabang proksimal dari Circle of Willis. Aterosklerosis merupakan penyebab utama dari penyakit pembuluh darah besar dimana trombi dapat terbentuk dari plak aterosklerotik yang merupakan $60 \%$ penyebab infark serebri. ${ }^{1}$

Iskemi serebral terjadi karena dua proses patofisiologis utama, yang pertama karena kekurangan pasokan oksigen dan glukosa yang disebabkan oklusi vakular, dan suatu urutan perubahan pada metabolisme seluler sebagai akibat dari kegagalan proses penghasilan energi, yang akhirnya merusak integrasi membran sel. ${ }^{9}$ Dari total 60 pasien afasia, persentase pasien stroke non hemoragik sebesar $60 \%$ dan stroke hemoragik $40 \%$, perbandingan ini sesuai dengan data epidemiologi yang selama ini menyatakan bahwa kasus afasia lebih banyak disebabkan oleh stroke nonhemoragik. ${ }^{1}$ Persentase dalam penelitian ini lebih rendah bila dibandingkan dengan penelitian Berthier ${ }^{2}$ yang menyatakan $80 \%$ kasus afasia disebabkan oleh stroke non hemoragik.

Berdasarkan sisi tubuh yang terkena, dari 60 pasien afasia, $47(78,3 \%)$ pasien mengalami hemiparesis dekstra, 6 (10\%) hemiparesis sinistra, 5 (8\%) hemiparesis dupleks dan 2 (3,3\%) pasien tanpa kelemahan.

Hemisfer serebral sinistra dari otak 
manusia terlibat dalam proses berbahasa vokal maupun manual, dibuktikan dengan adanya gangguan berbicara dan gangguan pada bahasa isyarat setelah adanya patologi pada hemisfer sinistra. Hemisfer sinistra juga terlibat dalam fungsi kontrol motorik dalam beberapa jenis gerakan nonkomuniftif baik oral maupun manual. ${ }^{38}$ Pada sebagian besar kasus, afasia terjadi pada pasien dengan stroke pada arteri serebral tengah sebelah kiri (left middle cerebral artery/LMCA). ${ }^{2}$

Banyaknya pasien afasia dengan hemiparesis dekstra sesuai dengan teori dan beberapa penelitian yang menyatakan bahwa pusat berbahasa berada pada hemisfer sinistra, sehingga apabila terjadi stroke pada hemisfer sinistra akan menyebabkan hemiparesis dekstra dan afasia., ${ }^{9,17-19}$

Pada penelitian ini, juga ditemukan pasien afasia dengan hemiparesis sinistra, dimana ini menunjukkan lokalisasi lesi pada hemisfer dekstra. Keunggulan fungsional satu hemisfer dibandingkan hemisfer lainnya merupakan dasar dari fungsi berbahasa. Perlu dicatat bahwa kecenderungan seseorang dalam memakai suatu sisi dengan lebih dominan berkembang secara simultan dengan bahasa. Terdapat beberapa tanda yang dapat menunjukkan bahwa satu hemisfer lebih dominan dari yang lain, salah satunya ialah adanya gangguan berbahasa yang terjadi akibat adanya suatu penyakit yang mengenai hemisfer yang lebih dominan. Pasien afasia dengan lesi pada hemisfer dekstra lebih jarang ditemukan, dan biasanya terjadi pada pasien yang lebih dominan menggunakan tangan kiri (left-handed). Tidak dapat dipungkiri adanya keterlibatan hemisfer yang non dominan pada proses berbahasa, namun hal ini belum didokumentasikan melalui penelitian secara anatomis. ${ }^{9}$ Adanya afasia pada pasien dengan hemiparesis sinistra dalam penelitian ini menunjukkan keterlibatan hemisfer dekstra dalam proses berbahasa. $^{20}$

\section{SIMPULAN}

Angka kejadian afasia pada stroke di Instalasi Rehabilitasi Medik RSUP Prof.
Dr. R. D Kandou Manado tahun 2015 ialah 13,2\% dari total 455 pasien stroke. Angka kejadian afasia pada pasien stroke terus meningkat pada setiap dekade di atas 30 tahun. Tidak terdapat perbedaan bermakna pada angka kejadian pasien afasia pada pasien laki-laki dan perempuan.

Afasia pada pasien stroke non hemoragik lebih banyak daripada pasien stroke hemoragik (3:2). Angka kejadian afasia tertinggi ditemukan pada pasien hemiparesis dekstra, namun afasia juga ditemukan pada pasien hemiparesis sinistra yang menandakan keterlibatan hemisfer dekstra dalam proses berbahasa.

\section{SARAN}

Perlu dilakukan penelitian lebih lanjut dengan cakupan yang lebih luas sehingga hasil yang didapatkan dapat mewakili populasi. Dapat juga dilakukan penelitian untuk mencari hubungan antara onset stroke dan afasia, angka kejadian dari setiap tipe afasia, dan masalah kognitif lainnya terkait stroke.

Disarankan agar Instalasi Rehabilitasi Medik mencatat tipe afasia secara lengkap serta untuk menyertakan hasil pemeriksaan CT Scan dengan deskripsi lokasi/topis lesi yang jelas sehingga dapat digunakan untuk penelitian selanjutnya.

\section{DAFTAR PUSTAKA}

1. Berthier ML, Davila G, Garcia-Casares N, Moreno-Torres I. Post-stroke aphasia. In: Schweizer TA, Macdonald RL, editors. The Behavioral Consequences of Stroke. New York: Springer, 2014; p. 95-118.

2. Berthier ML. Poststroke aphasia: epidemiology, pathophysiology and treatment. Drugs Aging. 2005;22:16382.

3. Pema WT. Aphasia-overview and teaching strategies. European Journal of Special Education Research. 2015;1(1):59-74.

4. Ranakusuma TAS. Lihai mendeteksi dini stroke dan pencegahan stroke berulang bagi awam dan dokter umum. Seminar Nasional Yayasan Stroke Indonesia Pertama. Jakarta, 2010.

5. Aho K, Harmsen P, Hatano S, 
Marquardsen J, Smirnov VE, Strasser T. Cerebrovascular disease in the community: results of a WHO collaborative study. Bull World Health Organ. 1980;58:113-30.

6. Szaflarski JP, Vannest J, Wu SW, DiFrancesco MW, Banks C, Gilbert DL. Excitatory repetitive transcranial magnetic stimulation induces improvements in chronic post-stroke aphasia. Med Sci Monit. 2011;25;17(3):CR132-9.

7. Truelsen T, Piechowskijozwiak B, Boniota R, Mathers C, Bogousslavsky J, Boysen G. Stroke incidence and prevalence in Europe: a review of available data. Eur $\mathbf{J}$ Neurol. 2006;13:581-98.

8. Badan Penelitian dan Pengembangan Kesehatan Departemen Kesehatan, Republik Indonesia. Riset Kesehatan Dasar 2013. Available from: http://www.depkes.go.id/resources/dow nload/general/Hasil\%20Riskesdas\%20 2013.pdf

9. Ropper AH, Samuels MA. Cerebrovascular diseases. In: Adams and Victor's Principles of Neurology (8th ed). New York: McGraw Hill, 2009; p. 3270-99.

10. Dickey L, Kagan A, Lindsay MP, Fang J, Rowland A, Black S. Incidence and profile of inpatient stroke-induced aphasia in Ontario, Canada. Arch Phys Med Rehabil. 2010;91:196-202.

11. Pedersen PM, Jorgensen HS, Nakayama H, Raaschou HO, Skyhoj Tom. Aphasia in acute stroke: incidence, determinants and recovery. Ann Neurol. 1995;38(4):659-66.

12. Zamani P, Mousavi SM, Rezai H, Madjdinasab N. Circadian variation in the incidence of stroke-induced aphasia types in Ahvaz, south-west of Iran. Jentashapir J Health Res. 2015;6(6): e28710.

13. Siirtola M, Narva EV, Siirtola T. On the occurence and prognosis of aphasia in patients with cerebral infarction. Scand J Soc Med Suppl. 1997;14:128-33.

14. Law J, Rush R, Pringle A-M, Irving A-M, Huby G, Smith M, et al. The incidence of cases of aphasia following first stroke referred to speech and language therapy services in Scotland. Aphasiology. 2009;23:1266-75.

15. De Renzi E, Faglioni P, Ferrari P. The influence of sex and age on the incidence and type of aphasia. Cortex. 1980;16(4):627-30.

16. Hier DB, Yoon WB, Mohr JP, Price TR, Wolf PA. Gender and aphasia in stroke data bank. Brain Lang. 1994;47(1):15567.

17. Kimura D. Left-hemisphere control of oral and brachial movements and their relation to communication. Philos Trans R Soc Lond B Biol Sci. 1982;298(1089):135-49.

18. Damasio A, Bellugi U, Damasio H, Poizner H, Van Gilder J. Sign language aphasia during left-hemisphere amytal injection. Nature. 1986;322:363-5.

19. Angiari P, Crisi G, Merli GA. Aphasia and right hemiplegia after cervical myelography with metrizamide. Neuroradiology. 1984;26(1):61-3.

20. Hagoort P, Brown CM, Swaab TY.Lexical-semantic event-related potential effects in patients with left hemisphere lesions and aphasia, and patients with right hemisphere lesions without aphasia. Brain. 1996;119(2): 627-49. 